\title{
Effects of Injection Speed and Fraction Solid on Tensile Strength in Semisolid Injection Molding of AZ91D Magnesium Alloy*1
}

\author{
Yuichiro Murakami, Kenji Miwa*2, Naoki Omura and Shuji Tada \\ National Institute of Advanced Industrial Science and Technology, Nagoya 463-8560, Japan
}

Semisolid injection molding is expected to be increasingly utilized as a forming process applicable to highly flammable magnesium alloys, since it can be carried out at temperatures lower than those of die casting. In this study, we investigated the effects of molding conditions on the tensile strength and internal casting defects of AZ91D magnesium alloy. Semisolid injection molding was conducted at injection speeds of 220, 300 and $400 \mathrm{~mm} \cdot \mathrm{s}^{-1}$ and fraction solids of $0.0,0.3,0.4$ and 0.5 . Whereas the volume fraction of casting defects decreased together with the decrease of injection speed, the mechanical strength reached a maximum at an injection speed of $300 \mathrm{~mm} \cdot \mathrm{s}^{-1}$. The investigation results show that in the solidification microstructure, $\alpha-\mathrm{Mg}$ and $\beta$ - $\mathrm{Mg}_{17} \mathrm{Al}_{12}$ phases, which were liquid during injection, were refined at higher injection speeds, suggesting that the tensile strength increases together with the injection speed if there are no casting defects. This trend might be due to the increased heat transfer coefficient between the mold and the slurry from the higher flow rate. On the other hand, the volume fraction of casting defects increased together with injection speed, and as a result the tensile strength deteriorated. When the injection speed was increased, the effects of decreased strength due to the increase in the volume fraction of casting defects counterbalanced the effects of increased strength due to the refinement of $\alpha-\mathrm{Mg}+\beta-\mathrm{Mg}_{17} \mathrm{Al}_{12}$ mixed phase. For this reason, the mechanical strength is considered to reach a maximum at an injection speed of $300 \mathrm{~mm} \cdot \mathrm{s}^{-1}$. Thus, we demonstrated that the tensile strength of semisolid products is affected not only by the volume fraction of casting defects, but also by the microstructure of the residual mixed phase precipitated, which is refined by increasing the injection speed [doi:10.2320/matertrans.F-M2012822]

(Received February 22, 2012; Accepted July 2, 2012; Published August 29, 2012)

Keywords: magnesium alloy, semisolid injection process, microstructure, mechanical properties, injection speed, fraction solid

\section{Introduction}

Recently, reducing the carbon dioxide emissions from vehicles has become an important topic of researches. Toward this end, lowering the weight of vehicles is an effective means of improving fuel economy and thus there is a need to extend the range of application of aluminum and magnesium alloys in the automotive industry. Various problems with the forming of magnesium alloys, however, remain to be solved. For example, liquid-phase magnesium alloys are highly combustible in air, making the use of a cover gas essential during the casting process. However, the global warming potential of $\mathrm{SF}_{6}$, which is a highly effective cover gas, is about 23900 times that of $\mathrm{CO}_{2}$.

The semisolid forming process is a method for manufacturing components with complex configurations, ${ }^{1-3)}$ and its recent application in the forming of aluminum alloys is attracting attention. ${ }^{4-8)}$ The viscosity of a semisolid metal is higher than that of the fully liquefied metal, and roughly half of the material is still solid. Therefore, it is expected that casting defects can be reduced by preventing air traps. Additionally, the dimension accuracy can be improved and draft angles can be reduced by decreasing the level of solidification shrinkage. Moreover, in applying this method to magnesium alloys, the risk of combustion is reduced due to the lower processing temperature and the relatively smaller amount of liquid magnesium.

We have developed a new type of the semisolid injection process that can be used in the forming of magnesium alloys. $^{9-12)}$ In this process, generic magnesium billet (rather

\footnotetext{
${ }^{* 1}$ This Paper was Originally Published in Japanese in J. JFS 84 (2012) 6874

*2Present address: Aichi Science and Technology Foundation, Kariya 4480013, Japan
}

than special billet for semisolid processing, such as thixo billet) is heated in an injection cylinder to a temperature at which a semisolid state is reached, and the resulting slurry is injected into a mold. The benefit of this process is a high material yield, and the use of a cover gas is not required since the semisolid magnesium alloy is not exposed to air.

In this study, plate specimens were made by using a testing machine implementing the proposed semisolid injection method, after which the effects of fraction solid and injection speed on the distribution of casting defects, the mechanical strength and the microstructure were investigated.

\section{Experimental Procedure}

\subsection{Injection molding experiment}

The semisolid injection molding experiment was carried out by using the vertical injection system shown in Fig. 1, where the injection cylinder was $25 \mathrm{~mm}$ in inner diameter, $60 \mathrm{~mm}$ in outer diameter and $475 \mathrm{~mm}$ in length; the nozzle was $3 \mathrm{~mm}$ in diameter and $6 \mathrm{~mm}$ in length.

The chemical composition of the AZ91D magnesium alloy used as the test material is given in Table 1. The injection cylinder in the apparatus was constantly filled with billet to a height of $320 \mathrm{~mm}$ under the nozzle, and the billet in the uppermost part of the cylinder was heated to a temperature range where a semisolid state was reached. The injection cylinder was equipped with six heaters (H1 to H6) mounted on the surface of the outer wall which were controlled independently on the basis of measurements from six type $\mathrm{K}$ thermocouples. The temperature of the billet in the uppermost part of the injection cylinder (from the nozzle to a height of $130 \mathrm{~mm}$ ) was controlled with precision of $\pm 1^{\circ} \mathrm{C}$ by setting the temperature of $\mathrm{H} 1$ (from the nozzle to a height of $21 \mathrm{~mm}$ ) and $\mathrm{H} 2$ (from the nozzle to a height of $151 \mathrm{~mm}$ ). The temperature distribution across the billet in the cylinder is 


\section{(J)}
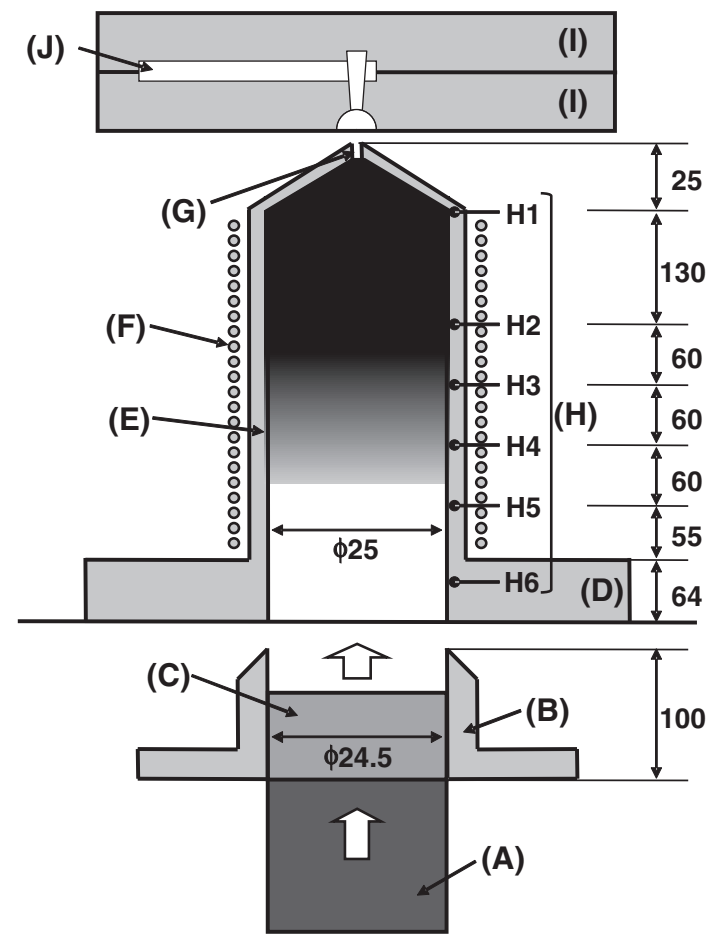

(A) Piston (B) Magazine (C) Billet (D) Cylinder base (E) Injection cylinder (F) Heating elements (G) Nozzle (H) Thermocouples (I) Permanent mold (J) Cavity

Fig. 1 Schematic drawing of the equipment used for testing the proposed semisolid forming technique.

Table 1 Chemical composition of AZ91D magnesium alloy.

$(\operatorname{mass} \%)$

\begin{tabular}{cccccccc}
\hline $\mathrm{Al}$ & $\mathrm{Zn}$ & $\mathrm{Cu}$ & $\mathrm{Fe}$ & $\mathrm{Mn}$ & $\mathrm{Ni}$ & $\mathrm{Si}$ & $\mathrm{Mg}$ \\
\hline 8.93 & 0.70 & 0.001 & 0.0017 & 0.25 & 0.0005 & 0.025 & Bal. \\
\hline
\end{tabular}

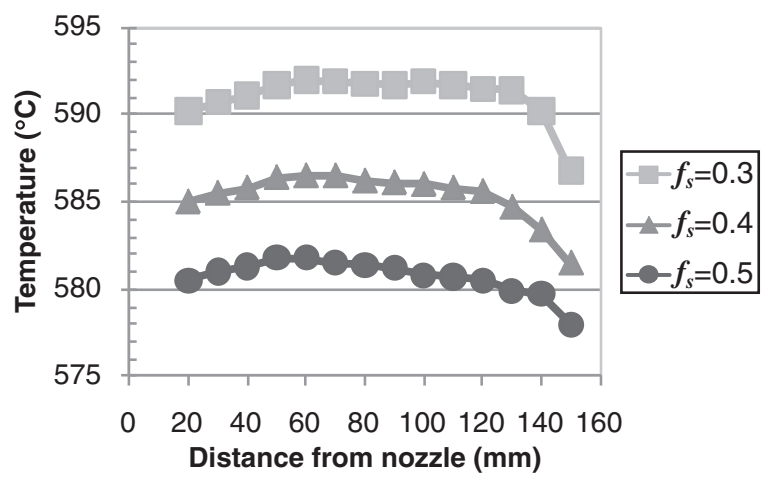

Fig. 2 Temperature distribution in the injection cylinder.

shown in Fig. 2. On the other hand, the temperature of the billet closer to the bottom was decreased by controlling the temperature of heaters $\mathrm{H} 3$ to $\mathrm{H} 6$, and billet at the bottom was in a solid state. Thus, a system with such design poses little or no risk of combustion since billet in the semisolid state is not exposed to air. Therefore, this experiment was carried out in air, without the use of a cover gas or inert gas.

Under these conditions, the billet was inserted into the injection cylinder by means of a hydraulic piston. As a result, semisolid billet was injected into the permanent mold from the uppermost part of the heated cylinder through the nozzle. In this setup, the extrusion ratio at the nozzle is approximately 70. After the injection, the temperature of the billet in the cylinder recovers within $10 \mathrm{~min}$, thus this process can be operated semi-continuously.

The permanent mold in the experiment was a plate cavity of $20 \mathrm{~mm}$ in width, $100 \mathrm{~mm}$ in length and $5 \mathrm{~mm}$ in thickness, and the slurry was injected horizontally since the mold was mounted vertically. The mold clamping force was set to $274.4 \mathrm{kN}$. The amount of injected slurry per cycle was about $30 \mathrm{~g}$, which was equivalent to the amount of material from the nozzle to a height of $53 \mathrm{~mm}$.

The temperature of the billet in the uppermost part of the injection cylinder (from the nozzle to a height of $130 \mathrm{~mm}$ ) was set to $611,591,586$ and $581^{\circ} \mathrm{C}$, where the corresponding values of the fraction solid $f_{\mathrm{s}}$ were $0.0,0.3,0.4$ and 0.5 . The injection speed, $V$, which was calculated from the average piston speed, was set to 220,300 and $400 \mathrm{~mm} \cdot \mathrm{s}^{-1}$. The flow speed of the slurry at the nozzle was 15.3, 20.8 and $27.8 \mathrm{~m} \cdot \mathrm{s}^{-1}$ at each of these injection speeds, respectively.

\subsection{X-ray computed tomography}

$\mathrm{X}$-ray computed tomography (X-ray CT) was carried out in order to examine the plate specimens for casting defects, where the direction of X-ray irradiation was perpendicular to the length direction of the specimens. The rendered images were created from cross-sectional images obtained with 3D rendering software (VGStudio Max 2.0, Volume Graphics Inc.). The volume fraction of casting defects was calculated from the difference in contrast between these rendered images. In addition, the resolution of X-ray CT was $46 \mu \mathrm{m}$, allowing for detection of casting defects greater than 8 voxels.

\subsection{Tensile test}

The plate specimens were mechanically processed into tensile test pieces after X-ray CT scanning. Each tensile test piece was $100 \mathrm{~mm}$ in length, $20 \mathrm{~mm}$ in width at the part where the sides were parallel, $25 \mathrm{~mm}$ in gage length, $8 \mathrm{~mm}$ in shoulder radius and $5 \mathrm{~mm}$ in thickness. In addition, the surface of the test piece was as cast. Tensile tests were carried out at room temperature by applying tension at a speed of $1.0 \mathrm{~mm} \cdot \mathrm{s}^{-1}$ to 5 samples per set of casting conditions.

\subsection{Microstructure observation}

The microstructure of the central part of the specimens was observed with an optical microscope. The samples were molded in epoxy resin and polished by grinding with $\mathrm{SiC}$ paper, followed by polishing with diamond paste. The samples were then etched with a solution of $75 \mathrm{~mL}$ ethylene glycol, $1 \mathrm{~mL}$ nitric acid and $24 \mathrm{~mL}$ distilled water.

\subsection{Measurement of cooling rate}

The temperature of the slurry during the injection process was measured with a thermocouple inserted into the mold, where the measurement point (shown in Fig. 3) was located $50 \mathrm{~mm}$ from the gate, $5 \mathrm{~mm}$ from the edge in width direction and $2 \mathrm{~mm}$ from the surface in thickness direction. The diameter of the thermocouple was $0.5 \mathrm{~mm}$, and the sampling 

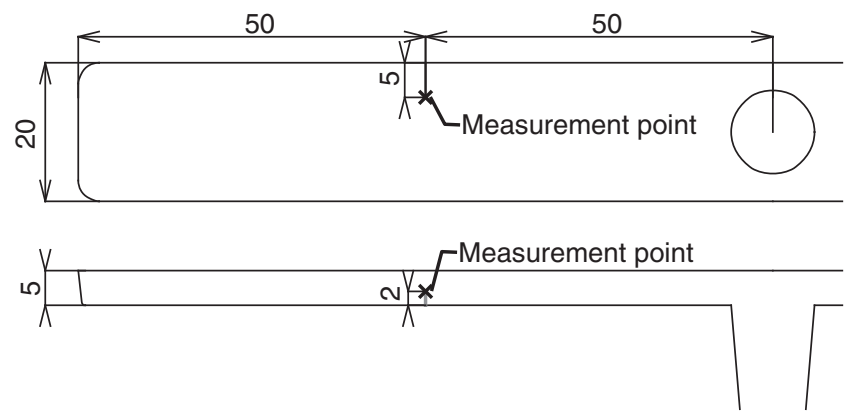

Fig. 3 Schematic representation of temperature measurement point in the permanent mold.

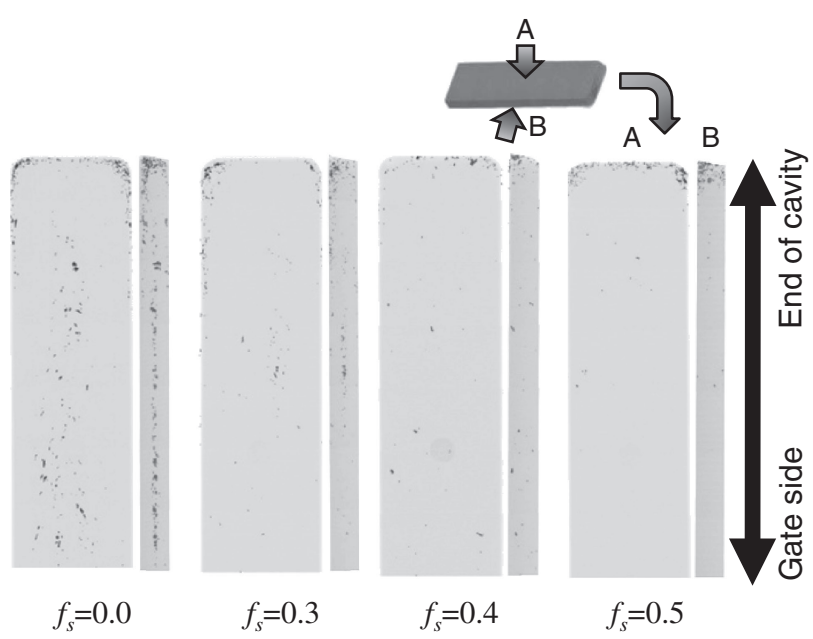

Fig. 4 Distribution of casting defects in the specimen prepared with an injection speed of $220 \mathrm{~mm} \cdot \mathrm{s}^{-1}$.

period was $0.5 \mathrm{~ms}$. The conditions during injection were set to a temperature of $591{ }^{\circ} \mathrm{C}$ and a fraction solid of 0.3 . Measurements were carried out at injection speeds of 220 and $400 \mathrm{~mm} \cdot \mathrm{s}^{-1}$.

\section{Results}

\subsection{X-ray computed tomography}

Volume rendering images of the specimens prepared with injection speeds of 220,300 and $400 \mathrm{~mm} \cdot \mathrm{s}^{-1}$ are shown in Fig. 4, Fig. 5 and Fig. 6, respectively. In these images, detected defects are shown in black. The volume fraction of casting defects was highest at $f_{\mathrm{s}}=0.0$ (which corresponds to fully liquefied material) at fixed injection speed, and it decreased in the case of semisolid injection as the fraction solid was increased. In addition, the volume fraction of casting defects decreased together with decrease of the injection speed. Specifically, at an injection speed of $220 \mathrm{~mm} \cdot \mathrm{s}^{-1}$, casting defects were detected at the center in thickness direction at $f_{\mathrm{s}}=0.0$, however, in the semisolid state, a large number of defects were detected at the end of the cavity. The reason for this discrepancy appears to be that the slurry could not be injected to the end of the cavity at low injection speeds due to its low fluidity. On the other hand, at injection speeds of 300 and $400 \mathrm{~mm} \cdot \mathrm{s}^{-1}$, casting defects appeared in the center of the specimens in thickness direction. These defects were attributed to air traps. The

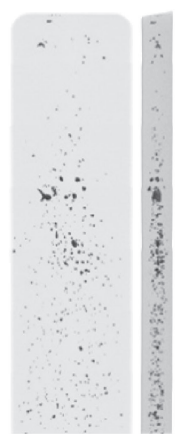

$f_{s}=0.0$ $f_{s}=0.3$

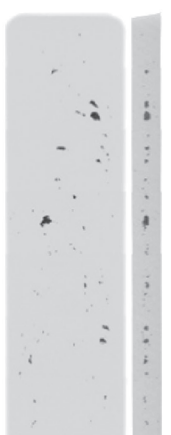

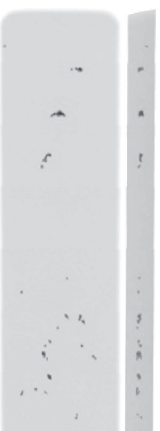

$f_{s}=0.4$

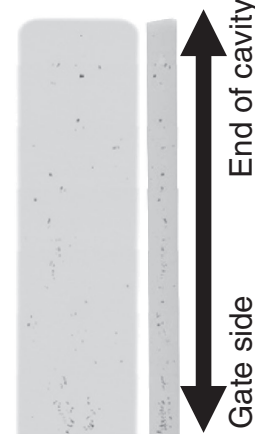

$f_{s}=0.5$
Fig. 5 Distribution of casting defects in the specimen prepared with an injection speed of $300 \mathrm{~mm} \cdot \mathrm{s}^{-1}$.

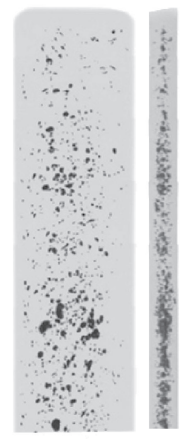

$f_{s}=0.0$

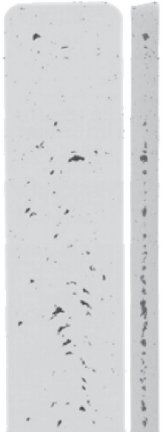

$f_{s}=0.3$

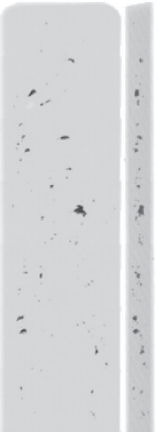

$f_{s}=0.4$

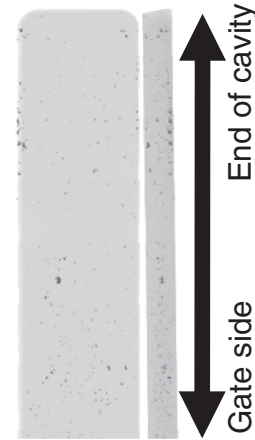

$f_{s}=0.5$
Fig. 6 Distribution of casting defects in the specimen prepared with an injection speed of $400 \mathrm{~mm} \cdot \mathrm{s}^{-1}$.

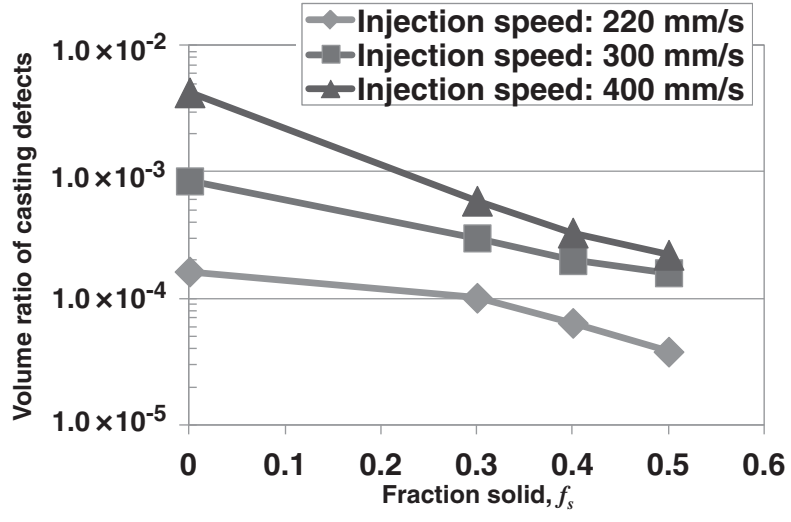

Fig. 7 Effect of fraction solid and injection speed on the volume of casting defects.

calculation results for the volume fraction of casting defects in each sample are shown in Fig. 7. The volume fraction of casting defects tended to decrease as the fraction solid was increased or the injection speed was decreased.

\subsection{Tensile test}

Figure 8 shows plots of the yield strength and tensile strength of specimens formed under each condition described above. Except for a fraction solid of 0.0 , both yield strength and tensile strength reached their respective maxima at an injection speed of $300 \mathrm{~mm} \cdot \mathrm{s}^{-1}$ and showed lower values at 


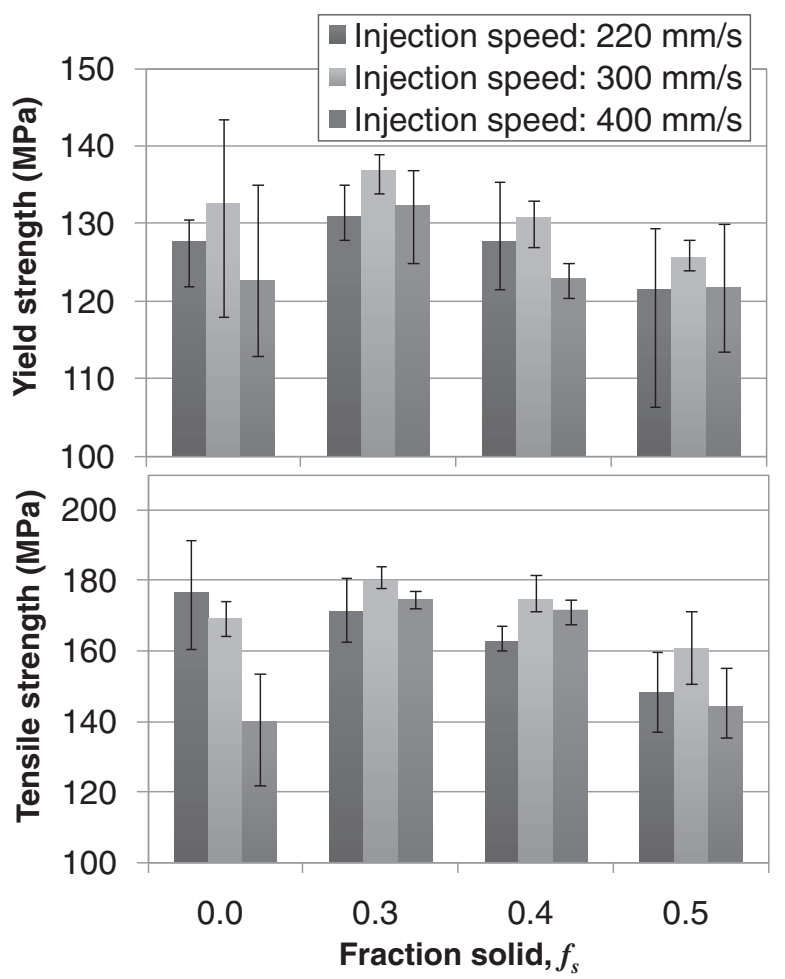

Fig. 8 Mechanical properties of the prepared specimens.

injection speeds of 220 and $400 \mathrm{~mm} \cdot \mathrm{s}^{-1}$. On the other hand, at a fixed injection speed, the strength reached a maximum at a fraction solid of 0.3 and decreased as the fraction solid was increased further. At an injection speed of $220 \mathrm{~mm} \cdot \mathrm{s}^{-1}$, the yield strength peaked at a fraction solid of 0.3 , however, the tensile strength was highest at a fraction solid of 0.0 .

\subsection{Microstructure observation}

Figure 9 shows a typical microstructure at the center of the specimen prepared with a fraction solid of 0.5 and an injection speed of $400 \mathrm{~mm} \cdot \mathrm{s}^{-1}$. These micrographs show that the microstructure of the specimen was homogeneous, with a uniform dispersion of primary $\alpha-\mathrm{Mg}$ in the matrix (eutectic $\alpha-\mathrm{Mg}$ and $\beta$ - $\mathrm{Mg}_{17} \mathrm{Al}_{12}$ ). Other specimens also showed the same characteristics. Furthermore, magnified micrographs of parts of the matrix for specimens injected under various conditions are shown in Fig. 10. The matrix forms a netlike structure of primary $\alpha-\mathrm{Mg}$ which tends to become finer as the fraction solid and the injection speed are increased.

\subsection{Measurement of cooling rate}

The temperature measurement results for slurry in the cavity at a fraction solid of 0.3 and injection speeds of 220 and $400 \mathrm{~mm} \cdot \mathrm{s}^{-1}$ are shown in Fig. 11. The cooling rate at each temperature as calculated from these measurement results is shown in Fig. 12. The cooling rate increased to its highest value after the temperature reached a maximum upon the slurry filling the cavity, after which it gradually decreased. At a temperature of $550^{\circ} \mathrm{C}$, the cooling rate for an injection speed of $400 \mathrm{~mm} \cdot \mathrm{s}^{-1}$ was $150^{\circ} \mathrm{C} \cdot \mathrm{s}^{-1}$ higher than that for an injection speed of $220 \mathrm{~mm} \cdot \mathrm{s}^{-1}$.

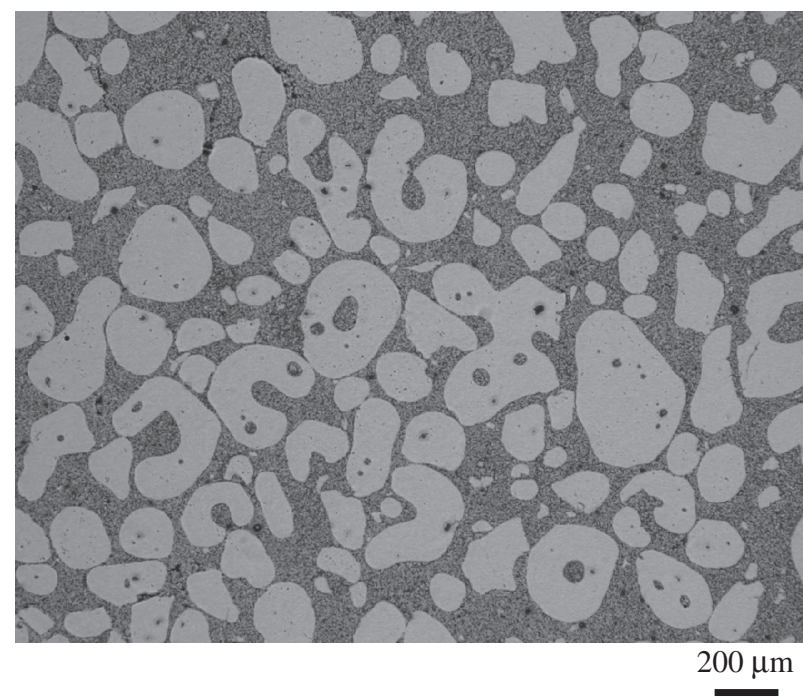

Fig. 9 Microstructure of the specimen prepared at an injection speed of $400 \mathrm{~mm} \cdot \mathrm{s}^{-1}$ and a fraction solid of 0.5 . It is composed of primary $\alpha-\mathrm{Mg}$ and eutectic phase.

\section{Discussion}

As shown in Figs. 4, 5 and 6, the tensile test pieces displayed casting defects in the part with parallel side; hence these casting defects are thought to affect mechanical strength. Figure 13 shows the relations between yield strength, tensile strength and volume fraction of the casting defects. At injection speeds of 300 and $400 \mathrm{~mm} \cdot \mathrm{s}^{-1}$, both yield strength and tensile strength decreased as the volume fraction of casting defects increased. These results agree with data obtained by other researchers. ${ }^{13)}$ At the same time, in comparison with the cases of injection speeds of 220 and $300 \mathrm{~mm} \cdot \mathrm{s}^{-1}$, the mechanical strength decreased despite the smaller volume fraction of casting defects in the case of $220 \mathrm{~mm} \cdot \mathrm{s}^{-1}$. On the other hand, for a fixed injection speed, the volume of casting defects decreased as the fraction solid was increased, although the mechanical strength reached a maximum at a fraction solid of 0.3 and decreased as the fraction solid was increased further.

The microstructure near the fracture surface of a tensile test piece is shown in Fig. 14. Fracture occurred in the $\alpha$ $\mathrm{Mg}+\beta-\mathrm{Mg}_{17} \mathrm{Al}_{12}$ mixed phase in the tensile test. Hence, the mechanical strength was strongly affected by the microstructure of the $\alpha-\mathrm{Mg}+\beta-\mathrm{Mg}_{17} \mathrm{Al}_{12}$ mixed phase.

The effect of the fraction solid on the mechanical strength is explained as follows. The volume fraction of casting defects decreased as the fraction solid was increased, thus increasing the mechanical strength. On the other hand, the ratio of $\beta-\mathrm{Mg}_{17} \mathrm{Al}_{12}$ in the $\alpha-\mathrm{Mg}+\beta-\mathrm{Mg}_{17} \mathrm{Al}_{12}$ mixed phase is thought to increase together with the fraction solid by concentration of dissolved $\mathrm{Al}$ atoms. An increase in $\beta-\mathrm{Mg}_{17} \mathrm{Al}_{12}$ content concentrated upon the $\alpha-\mathrm{Mg}+\beta$ $\mathrm{Mg}_{17} \mathrm{Al}_{12}$ mixed phase would impair the ductility and embrittle the mixed phase. Therefore, mechanical strength was thought to be decreased by increasing fraction solid. ${ }^{14)}$ Therefore, the mechanical strength reached a maximum at a fraction solid of 0.3 , where these two effects were balanced. ${ }^{11)}$ 


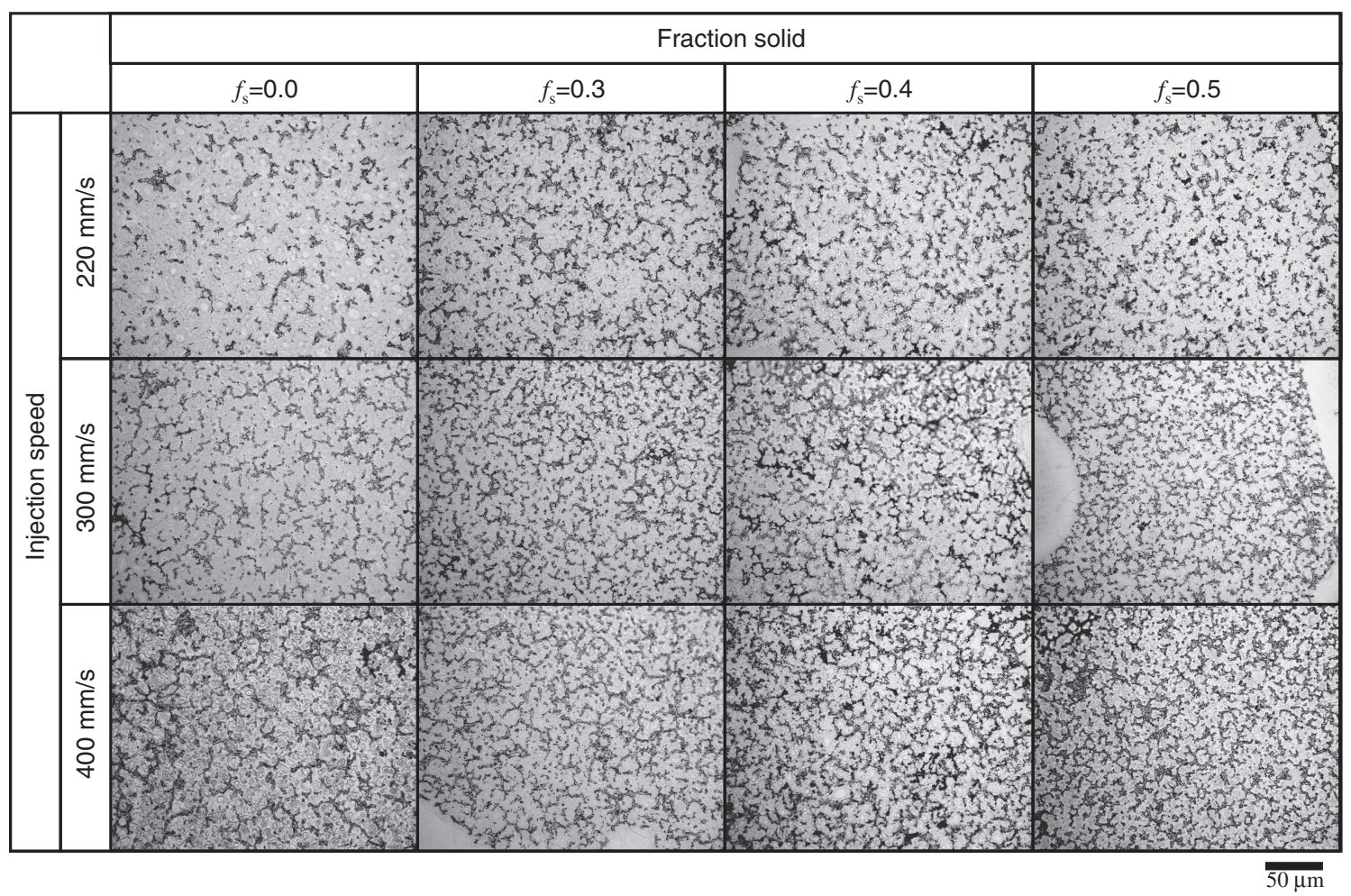

Fig. 10 Microstructure of the liquid phase of specimens prepared at various fraction solids and injection speeds.

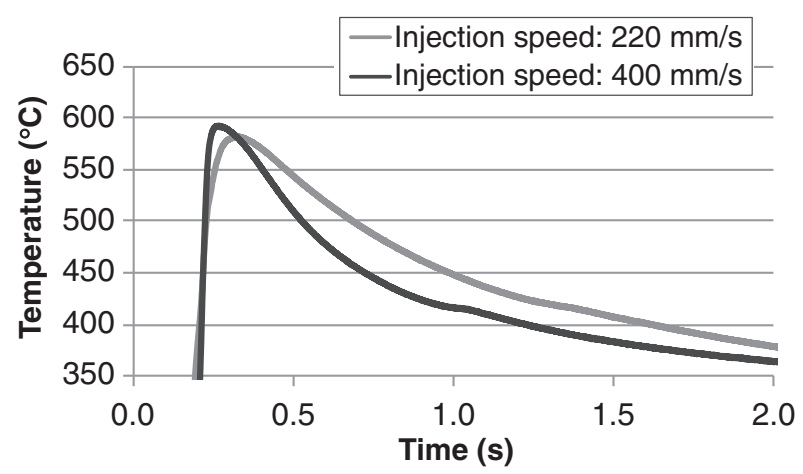

Fig. 11 Temperature measurement of slurry in the cavity at a fraction solid of 0.3 .

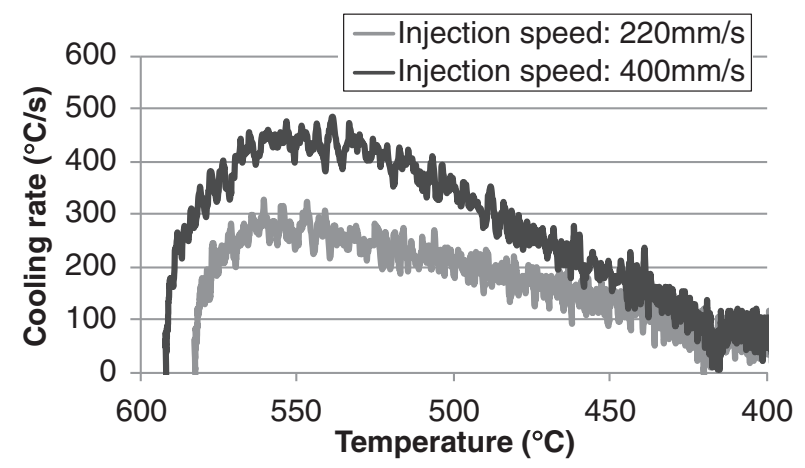

Fig. 12 Cooling rate of slurry injected in the cavity.

At the same time, the mechanical strength at an injection speed of $220 \mathrm{~mm} \cdot \mathrm{s}^{-1}$ was lower than that at an injection speed of $300 \mathrm{~mm} \cdot \mathrm{s}^{-1}$ despite the smaller volume fraction of casting defects. The reasons for this are considered to include

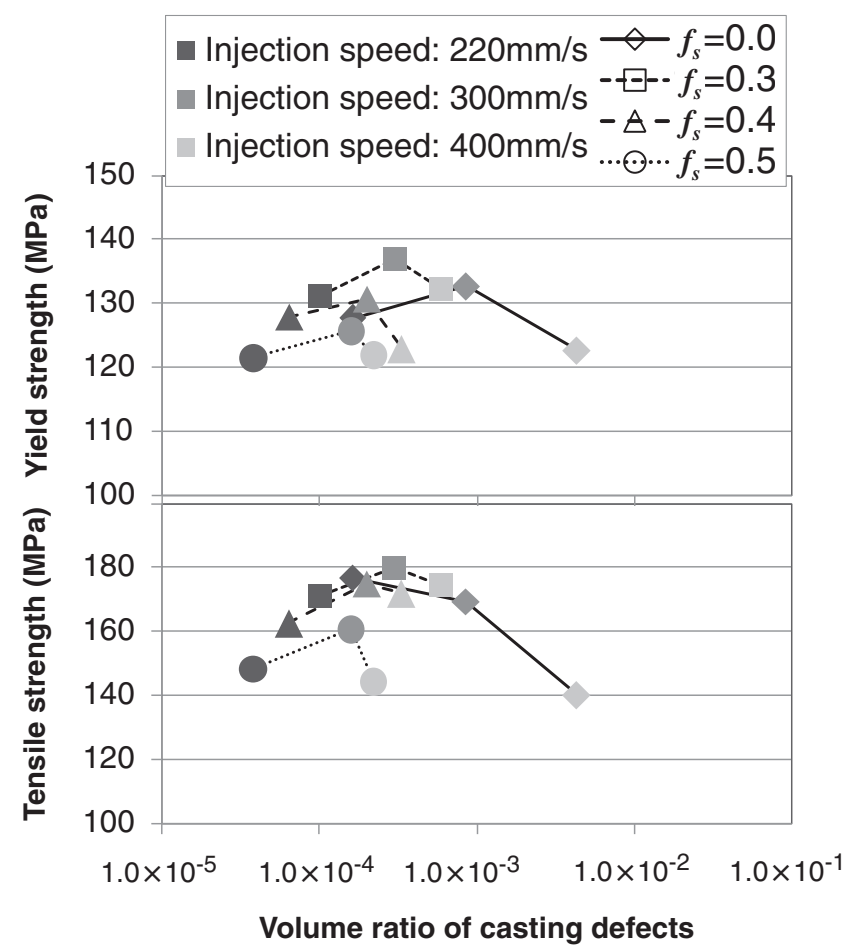

Fig. 13 Relation between volume ratio of casting defects and mechanical properties.

the tendency of the $\alpha-\mathrm{Mg}+\beta-\mathrm{Mg}_{17} \mathrm{Al}_{12}$ mixed phase to become fine as the injection speed is increased, as shown in Fig. 10. Thereupon, the fineness of the $\alpha-\mathrm{Mg}+\beta-\mathrm{Mg}_{17} \mathrm{Al}_{12}$ mixed phase was quantitatively evaluated based on the measurement procedure of dendrite arm spacing (DAS). $\left.{ }^{15}\right)$ Three segments were drawn between the borders of $\alpha-\mathrm{Mg}$ 


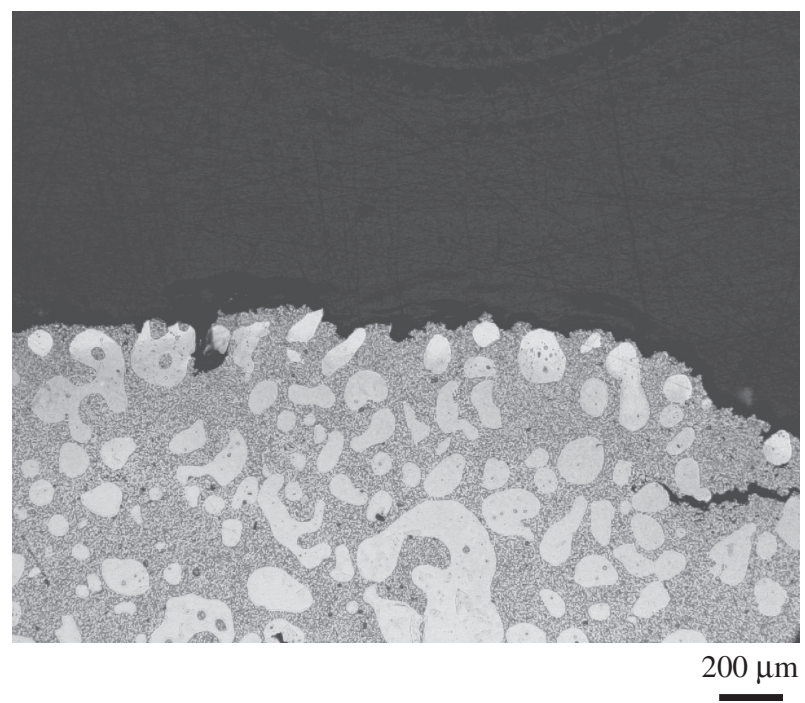

Fig. 14 Microstructure in the direction perpendicular to the fracture surface.

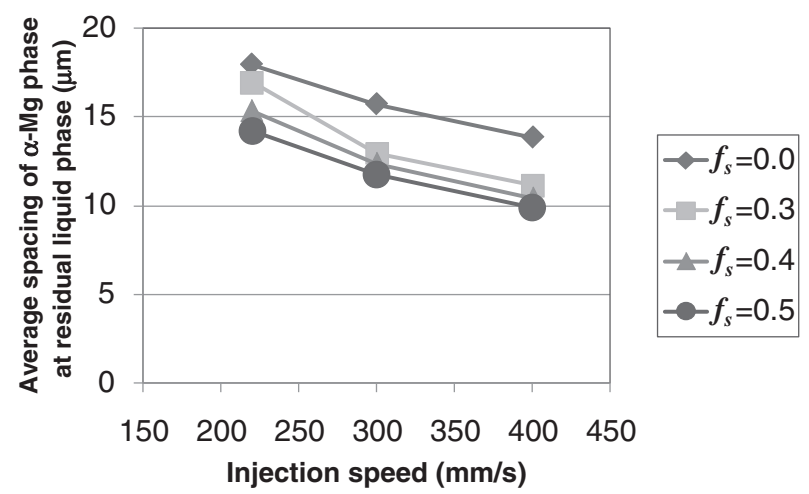

Fig. 15 Relation between average spacing of $\alpha-\mathrm{Mg}$ phases in liquid phase and injection speed.

phases in micrographs, and the average distance between $\alpha-\mathrm{Mg}$ phases was calculated as follows.

$$
\begin{aligned}
d & =\frac{l_{1}+l_{2}+\cdots+l_{m}}{\left(n_{1}-1\right)+\left(n_{2}-1\right)+\cdots+\left(n_{\mathrm{m}}-1\right)} \\
& =\frac{\sum l_{i}}{\sum n_{i}-\mathrm{m}}
\end{aligned}
$$

where $d$ is the average distance between $\alpha$-Mg phases, $l_{i}$ is the length of the $i$ th segment drawn between the border of $\alpha$ $\mathrm{Mg}$ phases in micrographs, $n_{i}$ is the number of intersection points between the $i$ th segment and $\alpha-\mathrm{Mg}$ phases, and $m$ is the number of measured segments.

The relation of the average distance between $\alpha-\mathrm{Mg}$ phases with the injection speed is shown in Fig. 15. The average distance between $\mathrm{Mg}$ phases decreased as the injection speed was increased for a fixed fraction solid. This result indicates that the solidification structure of the $\alpha-\mathrm{Mg}+\beta-\mathrm{Mg}_{17} \mathrm{Al}_{12}$ mixed phase is refined at higher injection speeds.

On the other hand, it is well known that the solidification structure is refined at higher cooling rates. The magnesium alloy AZ91 is characterized by the following relation between $d$ and the cooling rate $R .{ }^{16)}$

$$
d=A R^{\alpha}
$$

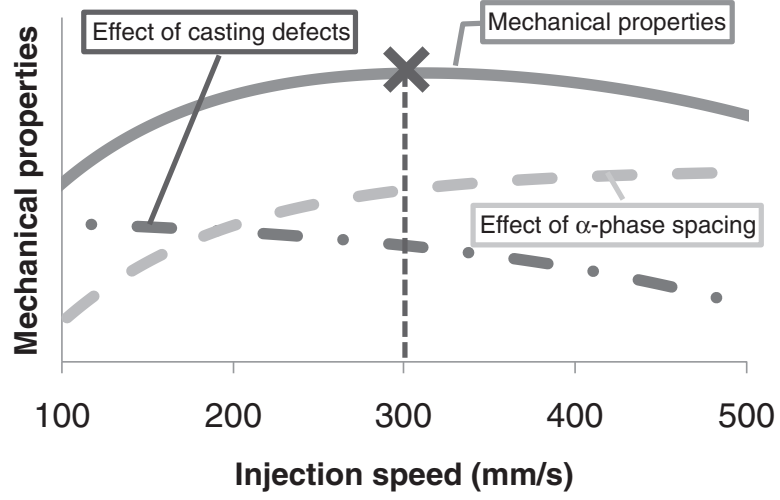

Fig. 16 Schematic relation between $\alpha$-Mg phase spacing, volume fraction of casting defects and tensile strength.

where $A$ and $\alpha$ are constants. When the injection speed is increased, the cooling rate increases (Fig. 12), which is considered to contribute toward the refinement of the $\alpha$ $\mathrm{Mg}+\beta-\mathrm{Mg}_{17} \mathrm{Al}_{12}$ mixed phase, as shown in Fig. 15 .

On the basis of these results, the effect of the injection speed on the mechanical strength is considered as follows. Initially, the decrease in mechanical strength was attributed to the increased volume fraction of casting defects caused by increasing the injection speed. On the other hand, the $\alpha$ $\mathrm{Mg}+\beta-\mathrm{Mg}_{17} \mathrm{Al}_{12}$ mixed phase, which strongly affects the mechanical strength, was refined at higher cooling rates, also as a result of increasing the injection speed. For these reasons, in the case of an injection speed of $400 \mathrm{~mm} \cdot \mathrm{s}^{-1}$, the specimens displayed fine microstructure, although with a large volume fraction of casting defects. On the other hand, for an injection speed of $220 \mathrm{~mm} \cdot \mathrm{s}^{-1}$, the volume fraction of casting defects in the specimens was small; however, the microstructure was coarse. Therefore, the mechanical strength was decreased at injection speeds of 220 and $400 \mathrm{~mm} \cdot \mathrm{s}^{-1}$, and the mechanical strength reached a maximum at an injection speed of $300 \mathrm{~mm} \cdot \mathrm{s}^{-1}$, where these effects were balanced, as shown in Fig. 16.

Guo et al. ${ }^{17)}$ showed that the heat transfer coefficient increases together with the injection speed in the case of high-pressure die casting. A similar trend is found in the semisolid injection process.

The mechanical strength of the semisolid molding product was affected not only by internal casting defects, but also by the microstructure of the $\alpha-\mathrm{Mg}+\beta-\mathrm{Mg}_{17} \mathrm{Al}_{12}$ mixed phase. Additionally, the structure of the $\alpha-\mathrm{Mg}+\beta-\mathrm{Mg}_{17} \mathrm{Al}_{12}$ mixed phase was refined at higher injection speeds.

\section{Conclusion}

To investigate the effects of fraction solid and injection speed on the volume fraction of casting defects and the tensile strength, experiments on semisolid forming of the AZ91D magnesium alloy were performed. The distribution of casting defects in the prepared specimens was examined by X-ray $\mathrm{CT}$, the mechanical strength was investigated by tensile testing, and microstructures were observed by optical microscopy. Additionally, the temperature of the slurry in the mold was measured during the injection process. As a result, the following conclusions were reached. 
(1) The volume fraction of casting defects decreases as the injection speed is decreased or the fraction solid is increased.

(2) The microstructure of the $\alpha-\mathrm{Mg}+\beta-\mathrm{Mg}_{17} \mathrm{Al}_{12}$ mixed phase, which constitutes the liquid phase when the slurry is injected, is refined by increasing the injection speed.

(3) The cooling rate of the slurry in the mold cavity increases together with the injection speed.

(4) When the injection speed is increased, the volume fraction of casting defects increases and it causes the mechanical strength to decrease. However, the $\alpha-\mathrm{Mg}+\beta-\mathrm{Mg}_{17} \mathrm{Al}_{12}$ mixed phase becomes finer and mechanical strength is increased. The mechanical strength of the specimens formed through this process reached a maximum under conditions that balanced these two effects, which was achieved at an injection speed of $300 \mathrm{~mm} \cdot \mathrm{s}^{-1}$.

\section{REFERENCES}

1) M. C. Flemings, R. G. Riek and K. P. Young: Mater. Sci. Eng. 25 (1976) 103.
2) P. A. Joly and R. Mehrabian: J. Mater. Sci. 11 (1976) 1393.

3) M. C. Flemings: Metall. Trans. B 22 (1991) 269.

4) W. G. Cho and C. G. Kang: J. Mater. Process. Technol. 105 (2000) 269.

5) H. K. Jung and C. G. Kang: J. Mater. Process. Technol. 120 (2002) 355.

6) S. Nafisi and R. Ghomashchi: J. Mater. Process. Technol. 174 (2006) 371.

7) T. Tsukeda and K. Saito: J. JFS 70 (1998) 697.

8) F. Czerwinski: Scr. Mater. 48 (2003) 327.

9) K. Miwa: J. Jpn. Soc. Technol. Plast. 41 (2000) 1210.

10) K. Miwa, R. S. Rachmat, T. Tamura and K. Sakaguchi: J. JFS 78 (2006) 193.

11) N. Omura, Y. Murakami, M. G. Li, T. Tamura and K. Miwa: Solid State Phenomena 141-143 (2008) 761.

12) Y. Murakami, N. Omura, M. G. Lee, T. Tamura and K. Miwa: J. JFS 83 (2011) 315

13) S. Hotta, K. Saruki, T. Asano and M. Nakamura: J. Jpn. Inst. Light Met. 39 (1989) 203

14) X. Zhang, T. Li, H. Teng, S. Xie and J. Jin: Mater. Sci. Eng. A 475 (2008) 194.

15) The Japan Institute of Light Metals (ed.): Measuring method of dendrite arm spacing and cooling rate of aluminum alloy (1988) p. 46.

16) C. H. Cáceres, C. J. Davidson, J. R. Griffith and C. L. Newton: Mater. Sci. Eng. A 325 (2002) 344.

17) Z. P. Guo, S. M. Xiong, B. C. Liu, M. Li and J. Allison: Int. J. Heat Mass Transfer 51 (2008) 6032. 